\title{
Design educacional em projetos de educação a distância: abordagens pedagógicas subjacentes
}

\author{
The teaching design in \\ distance-learning projects: \\ underlying pedagogical approaches
}

Patrícia Passos Gonçalves PALÁCIO*

\begin{abstract}
RESUMO: O design educacional é definido como fase inicial e norteadora de um projeto de Educação a Distância - EaD. É a partir de sua concepção que as abordagens teóricas e metodológicas de ensino e aprendizagem são previamente definidas e posteriormente se articulam para incorporar de modo flexível as necessidades de ajustes ou direcionamento que se fizerem presentes durante o percurso. A partir dessas premissas, no presente artigo serão discutidas as abordagens pedagógicas relacionadas ao design educacional de cursos a distância e os sinais que evidenciam a opção por determinados suportes teóricos.
\end{abstract}

Palavras-chave: educação a distância, design educacional, ambientes de aprendizagem, educação e tecnologia

ABSTRACT: Educational design is defined as being the initial and guiding phase in any project of Distance Education. From its conception, theoretical and methodological approaches to teaching and learning are previously defined and later are interlinked to meet the needs for adjustments or guidance which may appear during the course of events. From these assumptions, this article will discuss the pedagogical approaches related to teaching design in distance courses and the factors which account for the choice of specific theoretical support.

Key words: distance learning, teaching Design, learning environment, education and technology

*Especialista em Comunicação e Educação. Email: patpassos@terra.com.br

Olhar de professor, Ponta Grossa, 8(2): 139-146, 2005. 
Na escolha de uma modalidade de trabalho pedagógico deve-se considerar a intencionalidade do ato educativo, as caracteristicas e singularidades dos aprendizes, os recursos existentes ou que podem ser providenciados e outros fatores que possam interferir no trabalho, restringindo-o ou abrindo-lhe novas possibilidades. (PRADO e ALMEIDA, 2003).

Segundo o Dicionário de terminologia de Educação a Distância (2003), o planejamento inicial de um curso a distância define-se como a "fase de concepção do sistema de ensinoaprendizagem e de todos seus aspectos operacionais, sistemas de avaliação, seleção de métodos e meios instrucionais e projeto de materiais instrucionais a serem adquiridos ou elaborados".

Como o termo instrucional remete à idéia de treinamento, na área da Educação, atualmente, adota-se para essa fase o termo design educacional, que melhor se adequa às concepções pedagógicas envolvidas no processo de desenvolvimento de um ambiente de ensino e aprendizagem. Campos \& Rocha (1998, p. 15) descrevem essa etapa como:

um ciclo de atividades que, apoiado em uma teoria de aprendizagem, define os objetivos educacionais, as informações que constarão do produto e o modelo de avaliação. A seleção da melhor solução para o modelo é um problema que envolve princípios sócio-culturais do 'projetista', fatores externos impostos pelo ambiente e habilidades do aprendiz.

Destaca-se, desse modo, a importância da opção pela abordagem determinada implícita ou explicitamente no momento da estruturação do curso. Não só no que diz respeito ao conteúdo, mas especialmente com relação às interações e propostas de atividades, que carregam ou, na maioria das vezes, explicitam a natureza da intenção pedagógica do professor ou formador.

Santos e Campos (2003) corroboram essa afirmativa, quando citam que

os cursos à distância baseados na Web exigem a disponibilidade de sistemas e ambientes virtuais interativos que permitam o desenvolvimento de disciplinas apoiadas em métodos pedagógicos ativos. A aprendizagem não deve simplesmente refletir a realidade, mas construir uma interpretação significativa da mesma, a partir de problemas autênticos, significativos e contextualizados, levando em consideração os interesses do estudante.

Neste artigo, serão analisados, através de suportes teóricos, possíveis sinais que revelem as abordagens pedagógicas presentes no design educacional de cursos voltados à $\mathrm{EaD}$. 


\section{ABORDAGENS PEDAGÓGICAS PRESENTESEMEAD}

Em função da enorme diversidade de estágios de desenvolvimento e necessidades na área de Educação, nas diferentes regiões do país, o ensino a distância tem se mostrado cada vez mais uma alternativa viável para a melhoria da qualidade e aumento da quantidade de atendimento da demanda educacional. Conforme Campos (2003),

a educação a distância tem por base a compreensão de que, a partir dos anos 60, ela começou a distinguir-se como uma modalidade não convencional de educação, capaz de atender com eficiência, eficácia e qualidade aos anseios de universalização do ensino e, também, como meio apropriado à permanente atualização dos conhecimentos gerados de forma cada mais intensa pela ciência e cultura humana.

Partindo dessas premissas e tendo em vista a grande quantidade de cursos a distância oferecidos atualmente, observa-se que as vantagens e desvantagens dessa modalidade são entendidas por muitos autores e usuários de formas distintas: o que parece ser uma grande desvantagem para alguns, pode ser visto com ponto positivo para outros.

Segundo Valente (2003), existem diferentes maneiras de conceber a $\mathrm{EaD}$ e, dependendo da abordagem utiliza- da, ela pode ou não contribuir para o processo de construção de conhecimento. A abordagem conhecida como "broadcast" usa os meios tecnológicos para passar informação aos aprendizes. No outro extremo desse espectro de possibilidades está o suporte ao processo de construção de conhecimento via telemática, denominado de "estar junto virtual". Uma abordagem intermediária é a implementação da "escola virtual", que nada mais é do que o uso das tecnologias para criar a versão virtual da escola tradicional.

Essas formas mais tradicionais de transmissão de informação são amplamente difundidas através da rede e facilmente encontradas no formato de livro eletrônico. Esse tipo de material, apesar de ser intitulado "curso", na maioria das vezes não apresenta as características para assim ser considerado. Conforme definição de Azevedo (2003b), "curso é uma seqüência de atividades pedagógicas organizadas, planejadas, para atender objetivos de aprendizagem e que envolve fundamentalmente, quer na dimensão presencial quer na dimensão on line, interação coletiva".

Ainda segundo o mesmo autor, a especificidade da EaD está precisamente no fato de utilizar tecnologias que permitem novas formas de interação com conteúdos informativos. Como meio de comunicação diferenciado, ela permite também novas possibilidades de interação entre pessoas.

Observa-se, nesse sentido, que 
essa possibilidade de interação coletiva proposta no design educacional de um curso indica a intencionalidade da proposta pedagógica implícita, já que "uma perspectiva de interação e construção colaborativa de conhecimento favorece o desenvolvimento de competências e habilidades" (ALMEIDA, 2003a, p. 10) e que "os programas de $\mathrm{EaD}$ podem ter o nível de diálogo priorizado ou não segundo a concepção epistemológica e respectiva abordagem pedagógica" (ALMEIDA, 2003a, p. 6).

\section{RELAÇÕES DAS CONCEPÇÕES PEDAGÓGICAS COM O DESIGN EDUCACIONAL}

O design educacional de um curso a distância pode ser entendido como uma rede de associações entre conteúdo, concepção metodológica, ambiente digital, interação e avaliação, sendo esses elementos direcionados pela abordagem pedagógica definida como ponto de partida na elaboração da estrutura inicial do projeto.

Ao iniciar o design educacional de um curso, é fundamental "a identificação do usuário e a análise da tarefa a ser realizada com o auxílio de sistemas interativos" (SANTOS, 2003a, p. 2), pois, basicamente, existem dois modelos pedagógicos: o que tem por fundamento a transmissão de informação e outro que prioriza a interação e o diálogo como essência do processo educativo (AZEVEDO, 2003a).

Nesse sentido, projetar um ambi- ente de aprendizagem não é tarefa simples. Pressupõe a formação de uma equipe multidisciplinar, composta por professores com domínio do conteúdo e especialistas da área de informática. Campos (2001) ressalta que "cada membro da equipe precisa desempenhar um papel no processo de desenvolvimento e implantação do curso e cada papel exige diferentes competências, que resultarão em produtos próprios".

A projeção de tal ambiente requer, também, experiência no que diz respeito ao uso de tecnologias educacionais, mediação pedagógica e interatividade, de modo a priorizar na arquitetura do curso uma abordagem educacional que permita "integrar múltiplas mídias e recursos, apresentar informações de maneira organizada, desenvolver interações entre pessoas e objetos de conhecimentos, elaborar e socializar produções tendo em vista atingir determinados objetivos" (ALMEIDA, 2003a, p. 4).

Contextualizar as informações de forma que o modelo de ensino tradicional não seja transportado da sala de aula presencial para a virtual é outro aspecto importante a ser observado no design educacional. Propostas de atividades que possam gerar ações e reações plausíveis de manifestações tradicionais da prática de ensino, na maioria das vezes não são condizentes com as propostas em ambientes digitais, pois, como observa a autora supracitada, as interações devem propiciar trocas individuais e em grupos 
colaborativos que interagem, discutem, pesquisam, criam produtos e se desenvolvem.

Além da metodologia, deve-se também analisar que suporte tecnológico será utilizado. Alguns sistemas procuram ampliar os espaços de comunicação e interação entre os participantes de um curso, a fim de facilitar a passagem gradual de professores e estudantes da sala de aula presencial para a sala de aula virtual (SANTOS, 2003b).

Cabe ressaltar, no entanto, que nem todas as ferramentas para EaD disponíveis no mercado comportam a arquitetura educacional de um curso que contemple as formas de interações definidas pela equipe pedagógica, o que pode levar involuntariamente à alteração ou distorção da abordagem pedagógica pré-estabelecida pela equipe de desenvolvimento.

IDENTIFICAÇÃO DAS CONCEPÇÕES PEDAGÓGICAS SUBJACENTES NO DESIGN EDUCACIONAL

O design educacional de um curso a distância denota a intencionalidade pedagógica explícita e constitui a espinha dorsal das atividades a serem realizadas, sendo revisto e reelaborado continuamente no andamento das interações (Almeida, 2003a). As concepções pedagógicas, segundo Santos (2004), também se manifestam "pelo papel que o curso define para o aluno e pela forma de avaliação do desempenho".

Quando a abordagem educacional subjacente no design de um curso enfatiza a incorporação da realidade de cada aluno, dos grupos e da sociedade no processo educacional (PASS, 2001), pode-se reconhecer em sua concepção os princípios das teorias construcionistas. Nesse tipo de curso, a aprendizagem colaborativa, as propostas de discussão coletiva e a formação de grupos de trabalho são primordiais. A indicação de leituras complementares também é bastante utilizada, sempre acompanhada de uma proposta de discussão, pesquisa e troca de conhecimentos, visando à posterior socialização de informação e enriquecimento de suporte teórico.

Ao transpor essas situações para a Internet, pode-se utilizar ambientes de aprendizagem cooperativa ou criar um repositório de informações do trabalho em grupo, para registrar a comunicação entre os participantes, suas decisões e atividades, além das informações pessoais e atividades individuais de cada membro (Santos, 2004). Desse modo viabiliza-se a avaliação contínua e pode-se, ao final das atividades, obter uma visão geral acerca do desenvolvimento do curso.

Em contrapartida, há cursos que se caracterizam por priorizar a leitura de textos seguidos de exercícios para fixação dos conteúdos, do tipo "estímulo-resposta", ou "assinale a alternativa correta". Organizados por 
módulos, ao final de cada etapa são indicados outros textos para leitura, seguidos de exercícios de compreensão e assimilação de conceitos. As ferramentas para socialização do material produzido também são utilizadas em cursos dessa natureza, porém a discussão do grupo não é enfatizada e o foco está na produção individual.

Essas características denotam concepções baseadas nas teorias instrucionistas, em que a finalidade do processo educacional é levar o aluno a assimilar conteúdos, basicamente por memorização das informações fornecidas. Nesse tipo de abordagem, "o feedback deve ser constante e a avaliação é, de um modo geral, individual e através de testes objetivos. A interação e cooperação entre alunos não são aspectos fundamentais para a aprendizagem" (SANTOS, 2004).

Seguindo essa mesma linha, algumas equipes optam, ainda, pela elaboração de conteúdos didáticos disponibilizados, simultaneamente, em mídia impressa, como material de apoio para suprir supostas carências e ruídos observados no processo de aprendizagem a distância. Para esses tipos de cursos não são necessárias muitas tecnologias interativas, já que o processo educacional pressupõe auto-instrução.

Recursos de multimídia e hipertexto também podem sinalizar o tipo de abordagem pedagógica determinada no design educacional. Em abordagens construcionistas, ambos são inseridos no contexto para viabilizar a interatividade e despertar interesses voltados ao desenvolvimento do processo de aprendizagem, enquanto em cursos caracteristicamente instrucionistas são mais utilizados como atrativo visual e elementos de glossário.

Através dessas observações, pode-se concluir que os projetos de cursos a distância têm sido influenciados diretamente pelas teorias de aprendizagem que distinguem ambientes educacionais mais ou menos interativos, com maior ou menor grau de participação e controle do aluno sobre o seu processo de aprendizagem. A construção do conhecimento é viabilizada a partir da ação do sujeito no ambiente e esse diálogo é mediado pelo paradigma de programação implícito no meio digital (BARANAUSKAS, 1993).

Em resumo, cursos nos quais o aluno somente acessa informação e responde a testes objetivos individuais revelam, de um modo geral, uma concepção instrucionista. Já aqueles em que o aluno resolve problemas, aprende fazendo e é incentivado a pesquisar no contexto de um grupo, revelam uma visão mais próxima das abordagens construcionistas.

\section{CONSIDERAÇÕES FINAIS}

Por meio da análise de características marcantes presentes em cursos a distância, evidencia-se a opção por determinadas abordagens pedagógi- 
cas, assim como o uso conjunto de algumas delas que, em certos momentos, são mais ou menos referenciadas pelos modelos dos cursos. Partindo dessa premissa, torna-se possível elencar alguns itens que, privilegiados pelos educadores, podem contribuir para que a abordagem pedagógica pensada inicialmente para o desenvolvimento do conteúdo e das atividades do curso seja garantida ao máximo durante todo o processo.

Assim, ao conceber o design educacional em um projeto de $\mathrm{EaD}$, é importante primar pelo planejamento do curso como um todo e pelo estabelecimento prévio de objetivos a serem atingidos, levando-se em conta as características do público alvo, a finalidade de alcance do curso e a população atendida, inclusive no que diz respeito à escala. Deve-se ainda verificar, de acordo com o ambiente a ser utilizado, todas as possibilidades de interatividade e recursos que possam promover a aprendizagem colaborativa, além do estabelecimento de um processo de avaliação contínua.

Conclui-se que, com base em estudos teóricos e a partir de análises criteriosas de cursos a distância, é possível identificar as abordagens subjacentes ao processo de elaboração do design educacional, podendose revelar pressupostos pedagógicos presentes nos conteúdos e atividades sugeridas no transcorrer do curso.

Diante da relevância do tema, em função do aumento gradativo da quantidade de cursos a distância ofereci- dos, tanto no âmbito acadêmico como no corporativo, ressalta-se a importância de se prosseguir com análises dessa natureza, objetivando chegar a propostas educacionais mais efetivas e visando, cada vez mais, ao aumento da qualidade dessa modalidade de ensino.

\section{REFERÊNCIAS}

ALMEIDA, M. E. B. Formando professores para atuar em ambientes de aprendizagem interativos e colaborativos. São Paulo: PUC-SP, 2000. Disponível em: < http://www. nave. pucsp. br/doc/ formando. doc >. Acesso em: set. 2003.

. Educação a distância e tecnologia: contribuições dos ambientes virtuais de aprendizado. In: XXIII CONGRESSO DA SOCIEDADE BRASILEIRA DE COMPUTAÇÃO. Anais. .., Campinas, UNICAMP, 2003a.

Tecnologias e gestão do conhecimento na escola. In: VIEIRA, A. T. ; ALMEIDA, M. E. B. ; ALONSO, M. (Orgs.). Gestão educacional e tecnologia. São Paulo: Avercamp, 2003b.

AZEVEDO, W. A vanguarda (tecno-lógica) do atraso (pedagógico): impressões de um educador on-line a partir do uso de ferramentas de courseware. Disponível em: < http://www. aquifolium. com. br/ educacional/...>. Acesso em: set. 2003a.

E-learning como elemento de integração no processo educacional. Disponível em: $<$ http://www. aquifolium. com. br/educacional/... > . Acesso em: nov. 2003b.

BARANAUKAS, M. C. C. Uma aborda- 
gem construcionista ao design de um ambiente para programação em lógica. In: VALENTE, J. A. (Org.). Computadores e conhecimento: repensando a educação. Campinas: UNICAMP, 1993.

CAMPOS, F.; ROCHA, A. R. Design instrucional e construtivismo: em busca de modelos para o desenvolvimento de software. In: IV CONGRESSO RIBIE. Anais..., Brasília, DF, 1998. Disponível em: < http://www. niee. ufrgs. br/ribie98/ TRABALHOS/250M. PDF $>$.

CAMPOS, G. H. B. Mais sobre o design de projetos de EAD. Revista TI Máster - Escola Internet: Formação e Treinamento On-line. 21. ago. 2001. Disponível em: $<$ http://www.timaster.com.br/revista... $>$. Acesso em: fev. 2004

. Estado atual da educação a distância. Revista TI Master - Escola Internet: Formação e treinamento On-line. 20 dez. 2003. Disponível em: < http:// www.timaster.com.br/revista/... > . Acesso em: fev. 2004.

DICIONÁRIO de terminologia de educação a distância. Disponível em: < http:// www.estudefacil.com.br/dicionario/ dicionario_i.html >. Acesso em: set. 2003.

LÉVY, P. As tecnologias da Inteligência. São Paulo: Editora 34, 2001.

PAAS, L. Design educacional. Florianópolis: UFSC/LIED, 2001. Disponível em: < http://www.eps.ufsc.br/disc/ tecmc/... > . Acesso em: set. 2002.

PRADO, M. E. B. B.; ALMEIDA, M. E. B. Criando situações de aprendizagem colaborativa. In: VALLIN, C. et al. Educação a distância via Internet. São Paulo: Avercamp, 2003.

SANTOS, N. Design de interfaces de software educacional. Disponível em: < http://www.ieditora.com.br $>$. Acesso em: em set, 2003a].

Espaços virtuais de ensino e aprendizagem. Disponível em: < http:// www.ieditora.com.br $>$. Acesso em: set. 2003b.

Entrevista concedida à autora. Mensagem recebida por < nsantos@infolink.com.br>em 06jan. 2004.

; CAMPOS, F. Como planejar e ministrar cursos a distância de qualidade? Disponível em: < http:// www.ime.uerj.br >. Acesso em: out. 2003.

SILVA, M. Sala de aula interativa. Rio de janeiro: Quartet, 2001.

TELES, L. Designing Online Collaborative Learning Environments. In: CICLO DE TELECONFERÊNCIAS ENGENHEIRO - REFORMA E RENOVAÇÃO PEDAGÓGICA DA EDUCAÇÃO TECNOLOGIA, 2., 2001. Anais eletrônicos... 2001. Disponível em: < http:// www.engenheiro2001.org.br/artigos/...>. Acesso em: set. 2003.

VALENTE, J. A. Diferentes abordagens de educação a distância. Campinas: NIED/UNICAMP; São Paulo: CED/PUCSP. $<$ http://www.proinfo.gov.br/biblioteca/... >. Acesso em: set. 2003.

VYGOTSKY, L. S. A formação social da mente. São Paulo: Martins Fontes, 1984.

Encaminhado em: 21/03/05

Aceito em: 24/06/05 